\title{
EFFECT OF COGNITIVE BEHAVIOURAL THERAPY ON THE QUALITY OF LIFE OF PEOPLE WITH SCHIZOPHRENIA IN SOUTH-WEST NIGERIA
}

\section{Makanjuola John Osuolale ${ }^{1}$, Chiejina Edith Nkechi2 $^{2 *}$ and Umunnah Joseph $\mathrm{O}^{3}$}

${ }^{1}$ Lecturer II, Faculty of Nursing Science, University of Medical Sciences, Akure Campus, Ondo State, Nigeria. Email moj750@gmail.com

${ }^{2}$ Professor, Department of Nursing Science, Nnamdi Azikiwe University, Awka, Anambra State, Nigeria. Email: nkechichiejina@yahoo.com

${ }^{3}$ Reader, Department of Medical Rehabilitation, Nnamdi Azikiwe University, Awka, Anambra State, Nigeria. Email: jo.umunna@unizik.edu.ng

*Corresponding Author: E-mail: nkechichiejina@yahoo.com; Phone no: +2348037463279

Cite this article:

Makanjuola J.O., Chiejina E.N., Umunnah J.O. (2021), Effect of Cognitive Behavioural Therapy on the Quality of Life of People with Schizophrenia in South-West Nigeria. African Journal of Health, Nursing and Midwifery 4(3), 35-44. DOI: 10.52589/AJHNMCTO6TTTV.

\section{Manuscript History \\ Received: 13 May 2021 \\ Accepted: 27 May 2021 \\ Published: 7 June 2021}

Copyright $\odot 2020$ The Author(s). This is an Open Access article distributed under the terms of Creative Commons AttributionNonCommercial-NoDerivatives 4.0 International (CC BY-NC-ND 4.0), which permits anyone to share, use, reproduce and redistribute in any medium, provided the original author and source are credited.
Abstract: The quality of life (QoL) of patients with schizophrenia is impaired compared to the general population. This study aimed to evaluate the effect of Cognitive Behavioural Therapy (CBT) on the quality of life of people with schizophrenia in selected Neuropsychiatric Hospitals in South-West Nigeria. A quasiexperimental research design was adopted in the study, 60 participants with schizophrenia were selected purposely, 30 participants to the intervention group and another 30 participants to the control group. Eight sessions of CBT were given to each participant in the intervention group. Data were collected with the use of the WHO Quality of life Bref questionnaire. Data collected were summarized using frequency, percentages, mean score, and standard deviation to answer research questions. The hypotheses were tested using the MannWhitney U Test and Wilcoxon Test at 0.05 level of significance. The outcome revealed that there was an overall post-intervention improvement in the Quality of life among the participants in the intervention group with a mean value of $3.63 \pm 0.89$, Z-value 3.72, p-value <0.001, unlike the control group with a mean value of $2.90 \pm 0.85, Z$-value $=1.77, p$-value $=0.08 . C B T$ intervention with pharmacological management was effective in improving the quality of life in schizophrenic patients. CBT should be integrated into routine care given to schizophrenic clients in nursing interventions.

KEYWORDS: CBT, Intervention, Schizophrenia, Quality of life 


\section{INTRODUCTION}

Quality of life is a person's sense of well-being and satisfaction with his/her life circumstances, as well as a person's health status and access to resources and opportunities ${ }^{1}$. The quality of life (QoL) of patients with schizophrenia is impaired compared to the general population ${ }^{2}$. Thus, improving the quality of life of such patients is emphasized in clinical practice guidelines all over the world ${ }^{3}$. In caring for schizophrenic patients, interventions that only target symptoms are not enough, but a more holistic view is necessary for which the patient's QoL is a central concern ${ }^{4}$. Clinical practice guidelines for schizophrenia recommend psychosocial treatments in treating patients with schizophrenia ${ }^{3}$. In people with schizophrenia, existing findings suggest that symptoms have only a modest relationship to $\mathrm{QoL}^{1}$, whereas neurocognitive deficits, highly prevalent in schizophrenia, are key factors for poor everyday outcomes ${ }^{5}$. Studies investigating the linkage between cognitive performance, objective QoL, and subjective patient-rated well-being have reported conflicting results ${ }^{6}$. Some studies reported positive correlations between neurocognitive performance and objective QoL (as assessed by Heinrichs-Carpenter Quality of Life Scale) ${ }^{7,8}$. Other researchers, however, reported an inverse relationship between neurocognitive performance and subjective $\mathrm{QoL}^{6,9}$, or even no relationships between neurocognitive deficits and either objective or subjective quality of life. Although most studies have focused on the impact of CBT on relapse prevention and medication adherence for people with schizophrenia, limited evidence is found on the effect of CBT on schizophrenic patients' quality of life symptoms in South-West Nigeria. Therefore, this current study evaluated the effect of Cognitive Behavioural Therapy (CBT) on the quality of life of people with schizophrenia in selected Neuropsychiatric Hospitals in South-West Nigeria. The following questions guided the study: what is the pre-intervention status of quality of life in the physical, psychological, social and environmental domains in the control and intervention groups of people with schizophrenia? What is the post-intervention status of quality of life in the physical, psychological, social and environmental domains in the control and intervention groups of schizophrenic patients? What are the overall pre and postintervention quality of life as perceived by the control and experimental groups of people with schizophrenia?

\section{Study Hypotheses}

1. There will be no significant difference in the pre-intervention quality of life between the intervention and control groups of schizophrenic patients.

2. There will be no significant difference in the post-intervention quality of life between the intervention and control groups of schizophrenic patients.

3. There will be no significant difference between the pre and post-intervention scores of the overall quality of life in the control and intervention groups of schizophrenic patients 


\section{MATERIALS AND METHODS}

\section{Research Design}

A quasi-experimental research design was adopted in this study to evaluate the effect of Cognitive Behavioural Therapy (CBT) on the quality of life of people with schizophrenia in selected Neuropsychiatric Hospitals in South-West Nigeria. Federal Neuropsychiatric Hospital, Yaba, in Lagos State and Neuropsychiatric Hospital, Akure in Ondo State were the study areas.

\section{The population of the Study}

The population of the study were the male and female schizophrenic in-patients within the age range of 20-60 years who had spent at least two weeks on admission in Federal NeuroPsychiatric Hospital, Yaba, Lagos State and Neuro-Psychiatric Hospital, Akure, Ondo State. Patients with primary diagnoses of drug abuse or alcohol and general medical conditions were not included in the study.

\section{Sample Size and Sampling Methods}

A sample size of 60 participants was determined from the study population of 70 schizophrenic patients through the application of the Taro Yamane formula (1973). The purposive sampling method was used to select 30 participants to the intervention group and 30 participants to the control group.

\section{The instrument for Data Collection}

The instrument used for data collection for the study was a questionnaire titled World Health Organization Quality of Life Bref (WHOQOL- BREF) which has two parts. The first part contains respondents' demographic characteristics of gender, age, education, and marital status. The second part is organised into 26 sub-items, the first and second items are for the overall quality of life and level of client's satisfaction of health status, respectively. Other items are classified according to the affected needs of respondents in 4 domains. Domain 1 deals with physical needs which consist of question items Q3, Q4, Q10, Q15, Q16, Q17 and Q18 (e.g. Extent to which physical pain prevents you from doing what you need to do, How much do you need any medical treatment to function in your daily life? Do you have enough energy for everyday life? etc). Domain 2 deals with psychological needs which consist of question items Q5, Q6, Q7, Q11, Q19 and Q26 (e.g. How much do you enjoy life?, To what extent do you feel your life to be meaningful?, How well are you able to concentrate? etc). Domain 3 deals with social needs which consist of question items Q20, Q21 and Q22 (eg. How satisfied are you with personal relationships? How satisfied are you with your sex life? How satisfied are you with the support you get from friends?), and domain 4 deals with the environment which also consists of question items Q8, Q9, Q12, Q13, Q14, Q23, Q24 and Q25 (e.g. How safe do you feel in your daily life? How healthy is your physical environment? Have you enough money to meet your needs? etc). The WHOQOL-BREF is designed into a 5-point scale of Very poor/ Not at all/ Very dissatisfied/ Never = 1point, Poor/ A little/ Dissatisfied/ seldom = 2points, Neither poor nor good/ Neither satisfied nor dissatisfied/ Moderate amount/ Moderately/ Quite often $=3$ points, Good/Very much/ Mostly/ satisfied/ Very often $=4$ points, Very good/ Very satisfied/ Extreme amount/ extremely/ completely/ Always = 5points. Domain scores were scaled in a positive direction (i.e. higher scores denote a higher quality of 
life). WHOQOL-BREF is a validated standardized instrument. Copies of the instrument were given to two experts in psychiatry, a psychologist, and a statistician to determine the face and content validity of the instrument. The instrument was pre-tested using a split-half technique, 10 Schizophrenic patients were used for the reliability test. They were drawn from the Psychiatry/ Mental health department of a Federal Teaching Hospital that was different from the study area. The data were collected at one time from the respondents and subjected to analysis. Spearman-Brown coefficient of 0.825 for overall items was obtained, Physical health domain had Spearman-Brown coefficient of 0.719, Psychological health domain had 0.926, Social relationship domain had 0.616, and 0.572 for the Environment domain.

\section{Ethical Consideration}

All the ethical principles were strictly adhered to. The study was not commenced until full approval to conduct the study was given by the Research and Ethics Committee of Ondo State Ministry of Health, Akure, Ondo State, Nigeria and the Research and Ethical Committee of Federal Neuropsychiatric Hospital, Yaba, Lagos State, Nigeria. The researchers explained the CBT procedure, its importance and what the participants stand to benefit to the participants. Informed consent was obtained from the participants before the study commenced. Participation in the study was voluntary without any bias or coercion. The participants were informed that the right to withdraw from the study at any level as the study progressed was based on their decision without any harm. Also, the researchers ensured strict confidentiality by assuring anonymity in the coding and interpretation of data collected in the study.

\section{Method of Data Collection}

The researchers liaised with the psychotherapists who administered the CBT to the participants in the intervention group. Following the self-introduction of the researchers, the establishment of rapport, necessary consent and permission to participate in the study were sought from the participants. Upon accepting to participate in the study, informed consent was obtained. The contents of the instruments WHO quality of life [WHOQOL- BREF] were explained carefully to each of the participants who met the inclusion criteria and responses to each item were marked as guided strictly by the contents of the instrument. Pre-intervention data were collected from the participants in control groups for baseline assessment. The respondents in the control group were on their pharmacological management throughout the study. Postintervention data on the participants' quality of life were collected after the 8 weeks of CBT intervention from the control group with the use of WHO quality of life [WHOQOL- BREF]. The period of data collection for both groups was from July 2019 till August 2019. In the intervention group, pre-intervention data were obtained for baseline assessment, each participant in the intervention group received eight sessions of individual CBT intervention delivered by the clinical psychologists with each session lasting for 40 minutes. The Psychoeducation module of the intervention was delivered by the researchers to the intervention group in three sessions as part of CBT, each session lasting for 35 minutes. The Psychoeducation module contents consisted of the meaning given to Psychosis, stress vulnerability model, Socio-Environmental Stress, Protective and Risk factors. The first week was used for the introduction and collection of pre-intervention data from both intervention and control groups. Post-intervention data on the participants' quality of life were collected after the 8 weeks of CBT intervention from the intervention group with the use of WHO quality of life [WHOQOL- BREF]. 


\section{Data Analysis}

The data collected on the four domains of WHO QoL were converted to a 100\% scale with WHO conversion formula before they were coded for analysis. The mean score of items within each domain was used to calculate the domain score. Mean scores were multiplied by 4 to make domain scores comparable with the scores used in the WHO QoL-100 and subsequently transformed to a 0-100 scale. Coded data were analyzed. Percentage (\%) was used to determine the demographic characteristics of the participants. The research questions were answered with a mean score and standard deviation, while Mann-Whitney and Wilcoxon tests were used to test the stated null hypothesis at 0.05 level of significance using Statistical Package for Social Sciences [SPSS] version 25.

\section{RESULTS}

Demographic Characteristics of the Respondents

Table 1: Demographic Characteristics of the Respondents $\quad N=60$

\begin{tabular}{|c|c|c|c|c|}
\hline \multirow[t]{2}{*}{ Variables } & \multicolumn{2}{|c|}{ Control } & \multicolumn{2}{|c|}{ Intervention } \\
\hline & f & $\%$ & $\mathbf{f}$ & $\%$ \\
\hline \multirow[t]{2}{*}{ Gender } & 15 & 50 & 15 & 50 \\
\hline & 15 & 50 & 15 & 50 \\
\hline \multicolumn{5}{|l|}{ Educational Status } \\
\hline No formal education & 3 & 10.00 & 2 & 6.67 \\
\hline Primary & 9 & 30.00 & 9 & 30.00 \\
\hline Secondary & 8 & 26.67 & 9 & 30.00 \\
\hline Tertiary & 10 & 33.33 & 10 & 33.33 \\
\hline \multicolumn{5}{|l|}{ Marital Status } \\
\hline Single & 16 & 53.33 & 16 & 53.33 \\
\hline Married & 12 & 40.00 & 13 & 43.34 \\
\hline Separated & 2 & 6.67 & 1 & 3.33 \\
\hline
\end{tabular}

Table 1 shows that $15(50 \%)$ of the participants were males while $15(50 \%)$ of the participants were females in the control group. Also, among the intervention group, 15(50\%) of the participants were males while $15(50 \%)$ were females. 
Research Question 1: What is the pre-intervention status of the quality of life in the Physical health, Psychological health, Social relationship and Environment domains in the control and intervention groups of people with schizophrenia?

Table 2: Quality of Life status of the Intervention and Control groups at pre and postintervention.

\begin{tabular}{lccc}
\hline Domain & Intervention & Control & Differences b/w Means \\
\hline WHO QoL & Mean \pm SD & Mean \pm SD & \\
\hline Pre-intervention & & & \\
Physical health & $34.23 \pm 12.38$ & $45.57 \pm 7.62$ & 11.34 \\
Psychological health & $32.43 \pm 12.06$ & $64.40 \pm 12.07$ & 31.97 \\
Social relationship & $37.00 \pm 14.08$ & $52.70 \pm 10.90$ & 15.70 \\
Environment & $43.47 \pm 8.54$ & $57.83 \pm 10.83$ & 14.36 \\
Post-intervention & & & \\
Physical health & $42.70 \pm 11.92$ & $36.63 \pm 7.65$ & 6.07 \\
Psychological health & $43.97 \pm 11.25$ & $28.70 \pm 7.91$ & 6.27 \\
Social relationship & $46.77 \pm 16.24$ & $40.53 \pm 11.84$ & 4.43 \\
Environment & $53.40 \pm 8.50$ & $57.83 \pm 10.83$ & \\
Overall Quality of Life & & & \\
Pre intervention & $2.53 \pm 0.78$ & $2.60 \pm 1$ & \\
Post intervention & $3.63 \pm 0.89$ & $2.90 \pm 0.85$ & \\
\hline
\end{tabular}

Table 2 shows that the pre-intervention status of the quality of life in the Physical health domain in the intervention group was a mean of $\bar{x}=34.23, \mathrm{SD}=12.38$, Psychological health domain had a mean of $\bar{x}=32.43, S D=12.06$, Social relationship domain had a mean of $\bar{x}=37.00, S D$ $=14.08$ and Environment domain had mean of $\bar{x}=43.47, \mathrm{SD}=8.54$. For the control group, the means were: Physical health domain: $\bar{x}=45.57 \pm 7.62$, Psychological health $64.40 \pm 12.07$, Social relationship 52.70 \pm 10.90 , and Environmental domain $57.83 \pm 10.83$.

Research question 2: What is the post-intervention status of the quality of life in the physical, psychological, social and environmental domains in the control and intervention groups of schizophrenic patients?

Table 2 shows the post-intervention status of the quality of life in the Physical health, Psychological health, Social relationship and Environment domains of the intervention and control groups. The intervention group with the Physical health domain had mean and standard deviation values of $\bar{x}=42.70, S D=11.92$, the Psychological health domain had mean and standard deviation values of $\bar{x}=43.97, \mathrm{SD}=11.25$, Social relationship domain had mean and standard deviation values of $\bar{x}=46.77, \mathrm{SD}=16.24$ and Environment domain had mean and standard deviation values of $\bar{x}=53.40, S D=8.50$. For the control group, the mean of Physical health domain was $36.63 \pm 7.65$, Psychological health $28.70 \pm 7.91$, Social relationship 40.53 \pm 11.84 , and Environmental domain $57.83 \pm 10.83$. 
Research question 3: What are the overall pre and post-intervention quality of life as perceived by the control and intervention groups of schizophrenic patients?

The result in table 2 shows that the pre-intervention status scores of the overall quality of life among the intervention group were a mean value of 2.53 and the standard deviation value of 0.78 and among the control group were a mean value of 2.60 and the standard deviation of 1 . The post-intervention status scores of the overall quality of life among the intervention group were the mean value of 3.63 with the standard deviation value of 0.89 , and among the control group was the mean value of 2.90 with the standard deviation of 0.85 .

Hypothesis 1: There will be no significant difference in the pre-intervention quality of life between intervention and control groups of schizophrenic patients.

Table 3: Mann-Whitney $U$ test comparison of Quality of Life domain values between Intervention and Control Groups at Pre and Post-Intervention

\begin{tabular}{lcccc}
\hline Domain & Intervention & Control & & \\
\hline WHOQoL Domains & Mean \pm SD & Mean \pm SD & Z - value & P - value \\
\hline Pre-Intervention & & & & \\
Physical health & $34.23 \pm 12.38$ & $45.57 \pm 7.62$ & -4.38 & $<0.001^{*}$ \\
Psychological health & $32.43 \pm 12.06$ & $64.40 \pm 12.07$ & -6.28 & $<0.001^{*}$ \\
Social relationship & $37.00 \pm 14.08$ & $52.70 \pm 10.90$ & -1.63 & $<0.001^{*}$ \\
Environmental & $43.47 \pm 8.54$ & $57.83 \pm 10.83$ & -4.62 & $<0.001^{*}$ \\
Post-Intervention & & & & \\
Physical health & $42.70 \pm 11.92$ & $36.63 \pm 7.64$ & -2.25 & $0.024^{*}$ \\
Psychological health & $43.97 \pm 11.25$ & $28.70 \pm 7.91$ & -5.18 & $.001^{*}$ \\
Social relationship & $46.77 \pm 16.24$ & $40.53 \pm 11.84$ & -1.63 & 0.103 \\
Environmental & $53.40 \pm 8.50$ & $57.83 \pm 10.83$ & -1.39 & 0.166 \\
\hline
\end{tabular}

*Significant $p$-values

In table 3, Mann-Whitney test analysis of the pre-intervention quality of life between the intervention group and the control group shows that statistically significant differences were found in all domains of WHOQOL with physical health domain z-score 4.38, p-value <0.001; psychological health domain z-score 6.28 , p-value $<0.001$; social relationship domain $\mathrm{z}$-score 1.63 , p-value $<0.001$ and environment domain z-score 4.62, p-value $<0.001$.

Hypothesis 2: There will be no significant difference in the post-intervention quality of life between the intervention group and the control group of schizophrenic patients.

Mann-Whitney test analysis of the post-intervention quality of life between the intervention group and the control group shows statistically significant differences in the physical health domain with z-score 2.25 , p-value 0.024 and in psychological health domain with z-score 5.18, p-value 0.001. However, no significant differences were found in the social relationship domain with a z-score 1.63 , p-value 0.103 and in the environmental domain with $\mathrm{z}$-score 1.39 , p-value 0.166 (Table 3). 
Hypothesis 3. There will be no significant difference between the pre-and postintervention scores of the overall quality of life in the control and intervention groups of schizophrenic participants.

Table 4. Wilcoxon test comparison of the overall quality of life between intervention and control groups at pre and post-intervention.

\begin{tabular}{|llllc|}
\hline Groups & Pre-Intervention & Post-Intervention & & \\
\hline & Mean \pm SD & Mean \pm SD & z-value & p-value \\
\hline Intervention & $2.53 \pm 0.78$ & $3.63 \pm 0.89$ & -3.72 & $<0.001$ \\
Control & $2.60 \pm 1$ & $2.90 \pm 0.85$ & -1.77 & 0.08 \\
\hline
\end{tabular}

Table 4 showed that the overall quality of life result of the Wilcoxon test of pre and post Intervention scores of the Intervention group revealed significant difference with $\mathrm{z}=3.72$, $\mathrm{p}$ value $=<0.001$ while the control group revealed no significant difference between the pre and post Intervention scores of the overall quality of life with z-score $=1.77, p$-value $=0.08$

\section{DISCUSSION}

Findings from the study showed that schizophrenic participants who received CBT intervention had improved quality of life in the physical health domain with a mean value of 42.70 , psychological health domain with a mean value of 43.97 , and social relationship with a mean value of 46.77 compared with participants in the control group quality of life in physical health domain with a mean value of 36.63, psychological health domain with a mean value of 28.70 , and social relationship with a mean value of 40.53 (table 2). The higher the mean scores, the better the quality of life. This result shows that CBT with pharmacological treatment can improve the quality of life of patients with schizophrenia. These findings are in line with the findings of researchers ${ }^{10}$ who reported better quality of life among schizophrenic patients that had Cognitive Behavioural Therapy along with pharmacological treatment than those who were not exposed to Cognitive Behavioural Therapy intervention. However, some findings indicated that CBT had no significant impact on the quality of life of schizophrenics ${ }^{11}$. This difference in finding could be due to differences in the study design, sample size and the locations of the studies.

In the researcher's opinion, the improved quality of life in the physical health domain and psychological health domain, social relationship and environment domain among the participants who had CBT compared with those participants in the control group as well as the significant differences observed in the physical and psychological health in the intervention group (table $2 \& 3$ ) implies that when an individual is psychologically healthy, his/her physical health would be adequately balanced. Health is defined as the complete state of physical, mental, and social well-being ${ }^{12}$. Reports have shown a better quality of life among schizophrenic patients that had Cognitive Behavioural Therapy with pharmacological treatment than those who were not exposed to Cognitive Behavioural Therapy intervention ${ }^{10}$. Also, studies have shown that schizophrenic patients who were exposed to CBT intervention had improvement in quality of life than the control group who were not exposed to CBT in all the domains ${ }^{13}$. 
Findings from the study also showed that schizophrenic participants who received CBT had better (mean $=3.63$ ) perception of their overall quality of life than those in the control group (table 2). There was also significant difference between the pre and post-intervention status among the Intervention group $(z=3.72 ; p$-value $=<0.001)$ (table 4). Studies on schizophrenia and quality of life showed that participants who were on CBT intervention showed improvement in the overall quality of life $^{14}$. However, some studies indicate contrary findings $s^{15}$.

\section{CONCLUSIONS}

CBT when used with pharmacological therapy improved the quality of life of people with schizophrenia. Psychiatric nurses should update themselves on the skills required to administer CBT to the in-patients, and CBT should be integrated into routine care given to schizophrenic clients in nursing interventions.

\section{REFERENCES}

1. Eack SM, Newhill CE, Anderson CM, Rotondi AJ. Quality of Life for Persons Living with Schizophrenia: More Than Just Symptoms. Psychiatr Rehabil J. 2007;30(3):21922.

2. Bobes J, Garcia-Portilla MP. Quality of life in schizophrenia. In: Katschnig H., Freeman H., Sartorius N, editors. Quality of life in mental disorders. 2nd ed. England: Wiley, Chichester; 2006. p. 153-67.

3. National Institute for Clinical Excellence. Schizophrenia: core interventions in the treatment and management of schizophrenia in primary and secondary care. ci.nii.ac.jp. 2009.

4. WHO. Interventions that only target symptoms are not enough, but a more holistic view is necessary for which patients' QoL is a central concern [Internet]. 2008 [cited 2020 Jun 14]. Available from: https://www.google.com/search?sxsrf=ALeKk01FuJD7nSO8yDPZQ63lo5CQwcFBQ\%3A1592150696110\&source=hp\&ei=qErmXsbNA42 eUN7ukrAM\&q

5. Harvey PD, Siu CO, Hsu J, Cucchiaro J, Maruff P, Loebel A. Effect of lurasidone on neurocognitive performance in patients with schizophrenia: A short-term placebo- and active-controlled study followed by a 6-month double-blind extension. Eur Neuropsychopharmacol. 2013;23(11):1373-82.

6. Tolman AW, Kurtz MM. Neurocognitive predictors of objective and subjective quality of life in individuals with schizophrenia: A meta-analytic investigation. Schizophr Bull. 2012;38(2):304-15.

7. Addington J, Addington D. Social and cognitive functioning in psychosis. Schizophr Res. 2008;99(1-3):176-81.

8. Savilla K, Kettler L, Galletly C. Symptoms and Quality of Life in Schizophrenia. Aust N Z J Psychiatry. 2008;42:496-504.

9. Narvaez JM, Twamley EW, McKibbin CL, Heaton RK, Patterson TL. Subjective and objective quality of life in schizophrenia. Schizophr Res. 2008;98(1-3):201-8. 
10. Bechdolf A, Knost B, Nelson B, Schneider N, Veith V, Yung AR, et al. Randomized comparison of group cognitive behaviour therapy and group psychoeducation in acute patients with schizophrenia: Effects on subjective quality of life. Aust N Z J Psychiatry. 2010;44(2):144-50.

11. Laws KR, Darlington N, Kondel TK, McKenna PJ, Jauhar S. Cognitive Behavioural Therapy for schizophrenia - outcomes for functioning, distress and quality of life: A meta-analysis. BMC Psychol. 2018;6(1):1-10.

12. WHO. Constitution [Internet]. [cited 2020 Jun 14]. Available from: https://www.who.int/about/who-we-are/constitution

13. Siu CO, Harvey PD, Agid O, Waye M, Brambilla C, Choi WK, et al. Insight and subjective measures of quality of life in chronic schizophrenia. Schizophr Res Cogn. 2015;2(3):127-32.

14. Galuppi A, Turola MC, Nanni MG, Mazzoni P, Grassi L. Schizophrenia and quality of life: How important are symptoms and functioning? Int J Ment Health Syst. 2010;4:1-8.

15. Sim K, Mahendran R, Siris SG, Heckers S, Chong SA. Subjective quality of life in firstepisode schizophrenia spectrum disorders with comorbid depression. Psychiatry Res. 2004;129(2):141-7. 